\title{
Regulation of oxidative-restorative processes in secondary fermentation of wine materials in sparkling wine technology
}

\author{
Liliya Nerovnykh ${ }^{1,{ }^{*},}$ Natalya Ageyeva ${ }^{2}$, Zarina Dakhuzheva ${ }^{1}$, Zaur Meretukov $^{1}$ and Anna \\ Gneush $^{3}$ \\ ${ }^{1}$ Maikop State Technological University, 191, Pervomayskaya Str., 385000, Maykop, Republic of \\ Adygeya, Russia \\ ${ }^{2}$ Federal State Budgetary Scientific Institution North Caucasian Regional Research Institute of \\ Horticulture and Viticulture, 39, st. them. 40th Anniversary of Victory, 350000, Krasnodar, Russia \\ ${ }^{3}$ Kuban State Agrarian University named after I.T. Trubilin, 13, Kalinina Str., 350000, Krasnodar, \\ Russia
}

\begin{abstract}
The expediency of using preparations of dry inactivated (cell walls) yeast - glutaroma, salcline, bioproject, elivite and activite - in the technology of sparkling wines produced by classical and reservoir methods has been studied. Decreased activity of redox potential is found when using said preparations irrespective of method of secondary fermentation. The greatest effect is noted in the combined use of cell wall preparations and bentonite suspension. The use of glutaroma and elivite, as well as mixtures thereof with bentonite, provided the highest amount of antioxidant activity of sparkling wine in both secondary fermentation methods. During the secondary fermentation of the control sample, an increase in glutathione content was observed in the first 2 weeks, after which its concentration remained virtually unchanged for 90 days of observation. The introduction into circulation of glutaroma, activite, bioproject, salcline, activated the fermentation process, and the concentration of reduced glutathione increased. A marked increase in glutathione concentration was found in the combined use of bentonite suspension with glutaroma, elivite and bioprotect. The increase in glutathione content was observed during the whole period of observation. On the basis of the obtained data, the mechanisms of oxidation-reduction process in production of sparkling wines by classical and reservoir methods are justified.
\end{abstract}

\section{Introduction}

The quality of sparkling wines is directly dependent on the degree of oxidation. Often a number of sparkling wines when opening a bottle and pouring wine into a glass has a color from golden to yellow, which is connected with oxidative processes in secondary fermentation. In such wines oxidation also manifests itself in taste, giving the beverage unpleasant taste.

* Corresponding author: nerovnyx @ mail.ru 
At the same time, in the production of sparkling wines the appearance of oxidation tones is unacceptable, so it is necessary to control the direction of redox processes, preventing the formation of peroxide and oxidation of tartaric acid to oxalic and coal, and on the contrary, to stimulate biochemical processes of a reducing nature, accompanied by the accumulation of reductons that positively affect the addition of organoleptic qualities of the product $[1,2$, $3]$.

This is achieved in two ways. First, all technological techniques are aimed at reducing the level of oxidative-restorative potential by creating anaerobic conditions, inhibiting oxidative enzymes with sulphur dioxide, removing cations of iron and copper, which are catalysts of oxidative processes. Secondly, by using the reductive action of yeast containing a complex of enzymes, aromatizing substances and other substances released into wine in autolysis. Glutathione reductase reducing oxidized glutathione is of particular importance. At the same time in wine develops a refined flavor, the taste improves. The use of the protective properties of glutathione is one of the most modern methods of aroma storage. Glutathione is contained in plants, foods and grape berries. It is also the most common non-protein sulfur-containing compound present in almost all living organisms, including Saccharomyces cerevisiae yeast. Since glutathione cannot be added to wort or wine material in pure form, the use of dry yeast preparations enriched with glutathione becomes increasingly relevant. Dry inactivated yeast (DIY) also varies depending on the quality and amount of reduced glutathione. DIYs consist entirely of yeast biomass cells and contain a large number of insoluble cell walls, membranes and intracellular components. Each DIY preparation has its own specialization depending on the content of cell shells, soluble manoproteins and specific components - micronutrients, sterols, glutathione. Some among them are known:

- Glutar, is yeast shells containing a large amount of glutathione, is an antioxidant;

- Sellin, consists of the yeast cell shells of the species Saccharomyces cerevisiae representing an insoluble fraction of autolysed wine yeast cells;

- Bioprotect - a preparation containing the cell walls of the wine yeast Saccharomyces cerevisiae; shows antioxidant properties;

Elivite - cell shells containing a large amount of soluble polysaccharides of the cell membrane, which confers a sense of volume and roundness;

- Activite - contains inactivated yeast, thiamine; its application allows avoiding delayed process of alcohol (secondary) fermentation associated with nitrogen deficiency [4-9].

The above-mentioned biopreparations have an antioxidant effect and are also a means of immobilizing yeast. The use of immobilized microorganisms contributes to the smooth flow of mass exchange processes, increase of the contact surface of immobilized cells with the substrate, separation of growth and metabolism processes, which allows to maintain constantly high ability of microorganisms to convert substrates. In addition, at the interface of phases, nutrients and products of yeast autolysis are concentrated, as well as sorption of biologically active substances - enzymes, vitamins, amino acids and other growth stimulators, which in turn contributes to activation of life activity of microorganisms [10-12].

In connection with the above, studies of the feasibility of using biopreparations glutaroma, salcline, bioprotect, elivite, activite, and mixtures thereof with bentonite - in secondary fermentation of wine materials in the production of sparkling wines, as well as comparative assessment of their impact on the redox characteristics of sparkling wines and accumulation of reducing tones become relevant.

\section{Materials and methods}

A series of experiments were made in which secondary fermentation was carried out in a process tank (acratophore model) with the possibility of maintaining and measuring carbon dioxide pressure and complete sealing, as well as in bottles. Tank and circulation mixtures 
were prepared on the basis of a blend of wine materials Aligote, Riesling, Chardonnay, treated with tannivine together with gelitilar (both preparations produced by France) and cold at a temperature close to freezing point. In addition to the treated wine materials, reactivated cells of active dry yeast IOC 18-2007 (France) of the species Saccharomyces cerevisiae Killer (Bayanus), reservoir liquor, as well as depending on the variant:

- Bentonite suspension (control);

- Glutar (option 1);

- Selklin (option 2);

- Bioprotect (option 3);

- Elivite (option 4);

- Activate (option 5);

- A mixture of a suspension of bentonite and glutaroma (variant 6);

- Mixture of bentonite suspension and selcline (variant 7);

- Mixture of bentonite suspension and bioproject (version 8);

- Mixture of a suspension of bentonite and elivite (variant 9);

- Mixture of bentonite suspension and activite (variant 10).

For this purpose in experimental versions in dynamics of secondary fermentation level of oxidative-restorative potential $(\mathrm{OR}, \mathrm{mV})$ was determined by means of $\mathrm{pH}$-meter with attachment, value of antioxidant activity (AOA) in terms of TROLOX using flow-injection system with amperometric detector "TsvetYauza-AAA-01" (Russia). Glutathione concentration was determined by Rezyapkin 's B.I. methods and etc. in the modification of N.A. Vojnova and etc., 2009.

\section{Results}

Oxidative-restorative processes in wines, including sparkling ones, are caused by absorption of air oxygen during technological operations. The solubility of oxygen in wine depends on temperature, a spirtuoznost, the content of extractive substances. When temperature and extractivity increase, solubility of oxygen decreases, and when alcohol concentration increases, solubility increases. The maximum solubility of oxygen in wine can range from 8$10 \mathrm{mg} / \mathrm{dm}^{3}$. Part of the oxygen binds irreversibly to wine components as peroxide compounds. The content of "peroxide oxygen" in the wine can reach $3 \mathrm{mg} / \mathrm{dm}^{3}$. The value of oxidative-restorative potential indicates the degree of oxidation or reduction of the medium. The more wine contacts air oxygen, the higher its oxidative-restorative potential. Conversely, when it is in conditions that exclude air access, the potential gradually decreases to a certain value, which is called the limit potential. ORP in aerated wines is usually between 350 and $500 \mathrm{mV}$, in wines without air access - 100-150 mV [13-15].

The results obtained from the dynamics of the change in the value of ORP showed that the value of ORP decreases with an increase in fermentation duration both in classic secondary fermentation in bottles and in secondary fermentation in acratophore. This is due to the consumption of free oxygen by wine yeast cells, the consumption of oxygen in various chemical reactions. However, despite the same fermentation time, the final ORP values for bottle fermentation are much lower (176-264 mV) than for secondary acratophore fermentation (212-286 mV). In both cases, control samples were distinguished by the high ORP value both before and after fermentation. Importantly, the numerical values of ORP in the experimental samples varied even before fermentation began, due to the use of different biopreparations introduced into the circulation or reservoir mixture. 


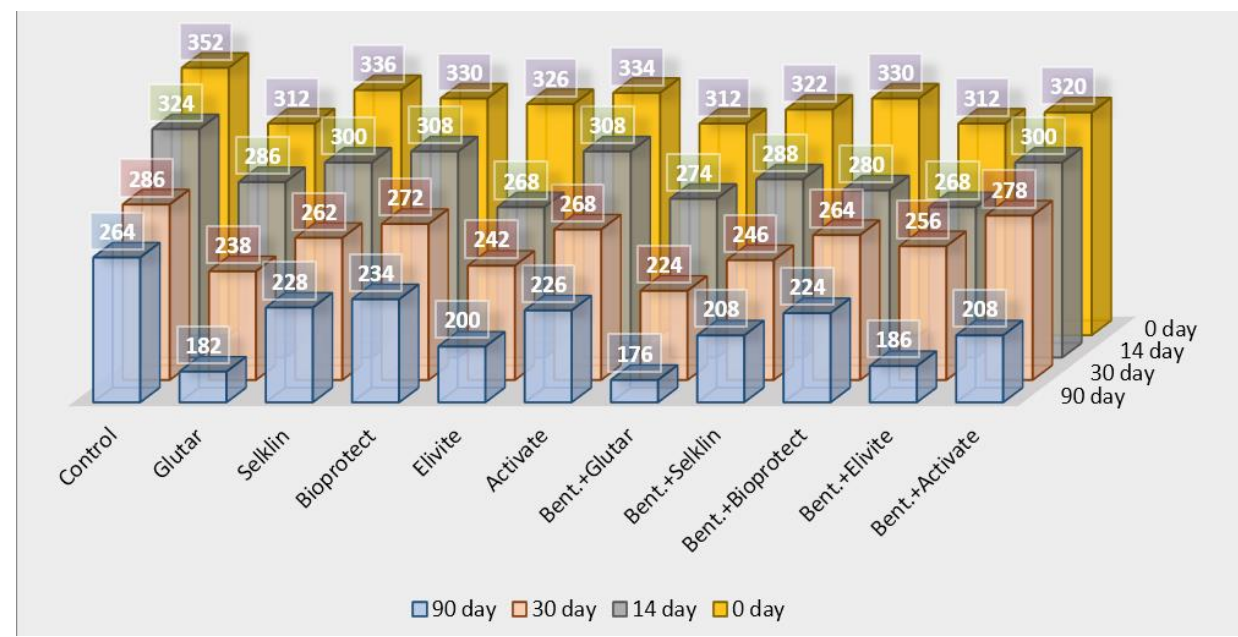

Fig. 1. Value change of redox potential in process of secondary fermentation in bottles, $\mathrm{mV}$.

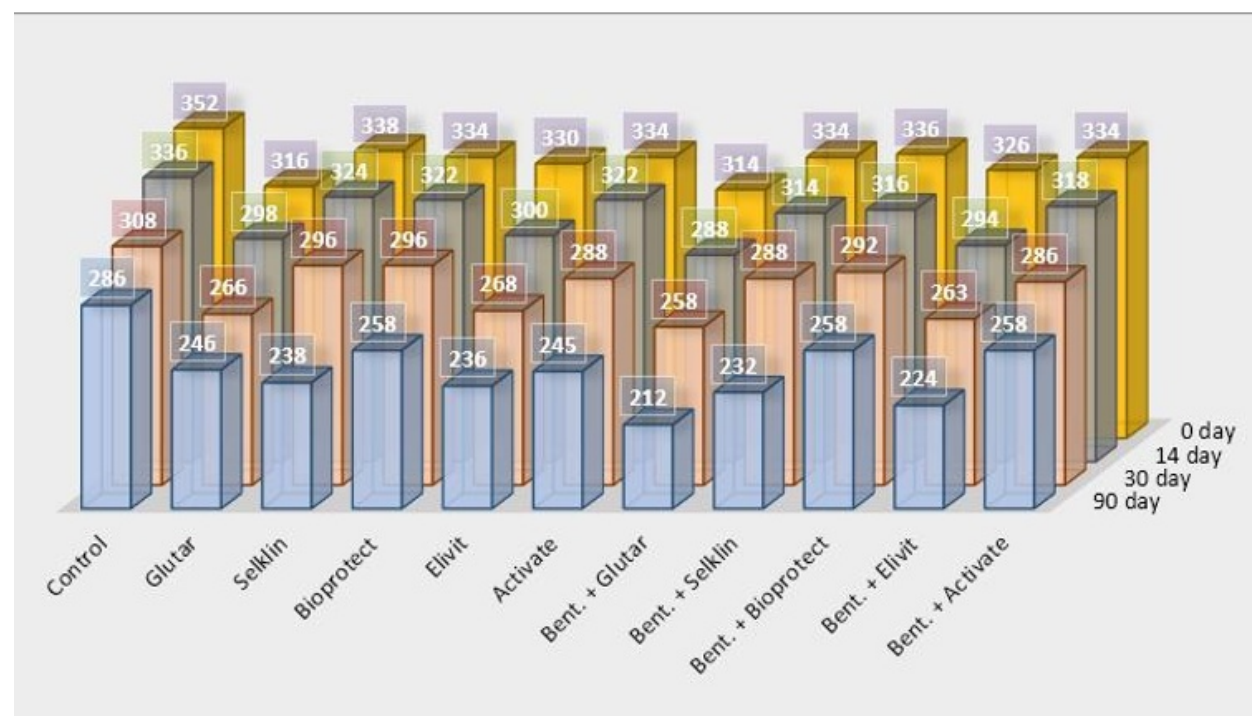

Fig. 2. Value change of redox potential in process of secondary fermentation in tanks, $\mathrm{mV}$.

Thus, the use of biopreparations, and especially glutaroma, led to a decrease in the value of ORP even before the onset of secondary fermentation, i.e. in contact with the contents of the circulation or reservoir mixture, which confirms the antioxidant properties of these preparations. The use of mixtures of the same yeast cell wall preparations together with bentonite provided a large reduction in the value of ORP when added to the circulation mixture. This is due, first, to the increase in the fermentation activity of wine yeast, second, to the ability of biopreparations to sorb oxidative enzymes. When their mixtures with bentonite are used, a synergistic effect is exhibited - the sorbing capacity is further increased compared to each preparation alone. In addition, glutar and, especially elivite, adsorbing fatty acids - fermentation inhibitors, and delivering sterols and vitamins, contribute to fermentation activation and oxygen consumption.

As noted above, during secondary fermentation under anaerobic conditions, a decrease in ORP was observed, both in bottle fermentation and in acratophore. However, in bottles, ORP had lower values compared to similar fermentation variants in the acratophore. This fact 
makes it possible to consider that when fermentation in acratophore the presence of free molecular oxygen provides a longer course of oxidative processes, which remains after 90 days. This may be one of the reasons for the appearance of golden and even yellow colors in ready-made sparkling wines.

The lowest ORP value was observed in samples where glutar was added to the circulation mixture or mixed with bentonite regardless of the secondary fermentation method. This is because glutathione, in the glutaroma composition, reduces hydrogen peroxide and dehydroascorbic acid, which helps to maintain ascorbic acid in a reduced state and maintain its antioxidant action in a medium that maintains reducing processes during secondary fermentation. In addition, the strong sorption capacity of bentonite and other clay minerals to oxidative enzymes is known, especially peroxidase catalyzing oxidative processes in wines. Peroxidase is an enzyme that accelerates oxidation of wine substances with peroxides, is not active in wine, so it can cause only extremely slow but long-term oxidation process, and the presence of iron and copper cations even in low concentrations, contributes to the displacement of H-processes towards oxidation. Therefore, the use of sorbent mixtures has an effective positive effect on inactivation of oxidative processes.

Versions with introduction of elivite and its mixture with bentonite into the composition of the circulation or reservoir mixture were also characterized by low value of ORP regardless of the method of secondary fermentation. According to the data inhibition of fatty acid accumulation leads to decrease of activity of oxidative enzymes, especially tyrosinase, which leads to decrease of ORP level and increase of antioxidant activity of medium.

The remaining sorbents and mixtures thereof with the bentonite suspension had similar results in the magnitude and dynamics of the OR.

Analysis of the dynamics of ORP change showed a significant decrease on the 14th-30th day in bottle fermentation and on the 30th-90th - in acratophore fermentation, which suggests not only oxygen consumption by physiologically active yeast cells, but also inhibition of oxidative enzymes.

The data obtained are fully consistent with the antioxidant activity (AOA) of the experimental samples. Antioxidant activity is one of the most important characteristics of the biological activity of the compounds. The main task of the antioxidant is to neutralize free radicals resulting from some processes in the cell of a living organism and capable of attacking vital targets if the natural mechanism of their neutralization is unable to cope with this task.

White wines, including sparkling wines, possess AOA, the magnitude of which is much smaller than in red wines. AOA white wines are provided by ascorbic, citric tartaric, succinic acids, amino acids, sulphurous substances. In addition, maintaining secondary fermentation under hermetic conditions and sufficiently long-term contact of wine with yeast precipitate results in autolysis of wine with antioxidants of wine yeast, especially amino acids. 


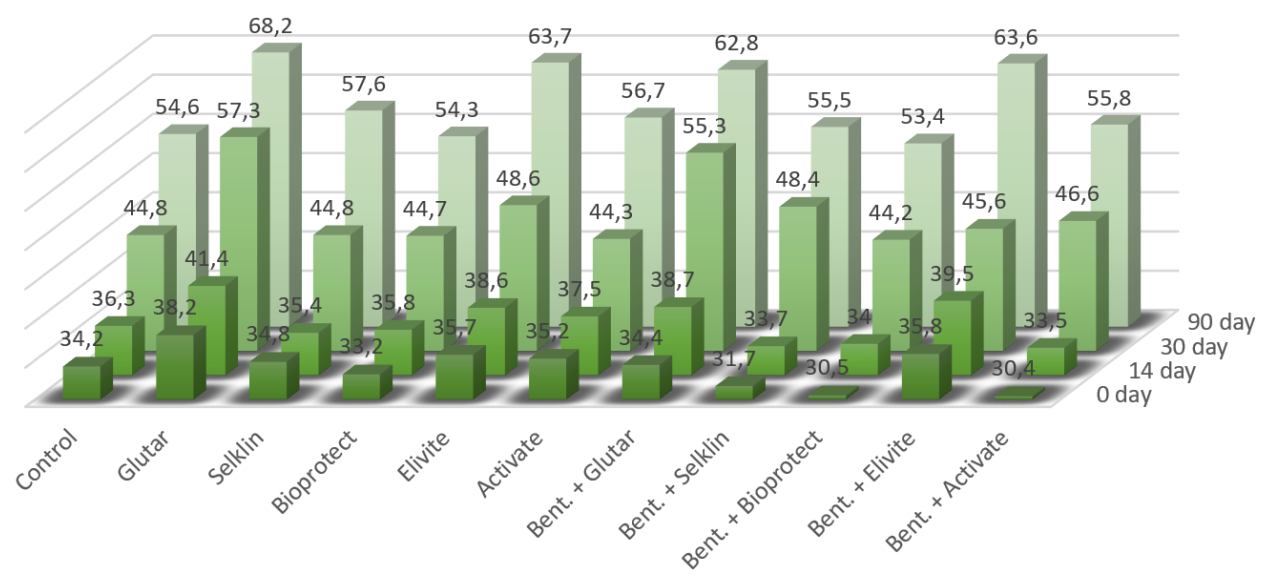

Fig. 3. Value change of antioxidant activity (AOA) in process of secondary fermentation in bottles, $\mathrm{Mg} / \mathrm{dm} 3$, in terms of TROLOX.

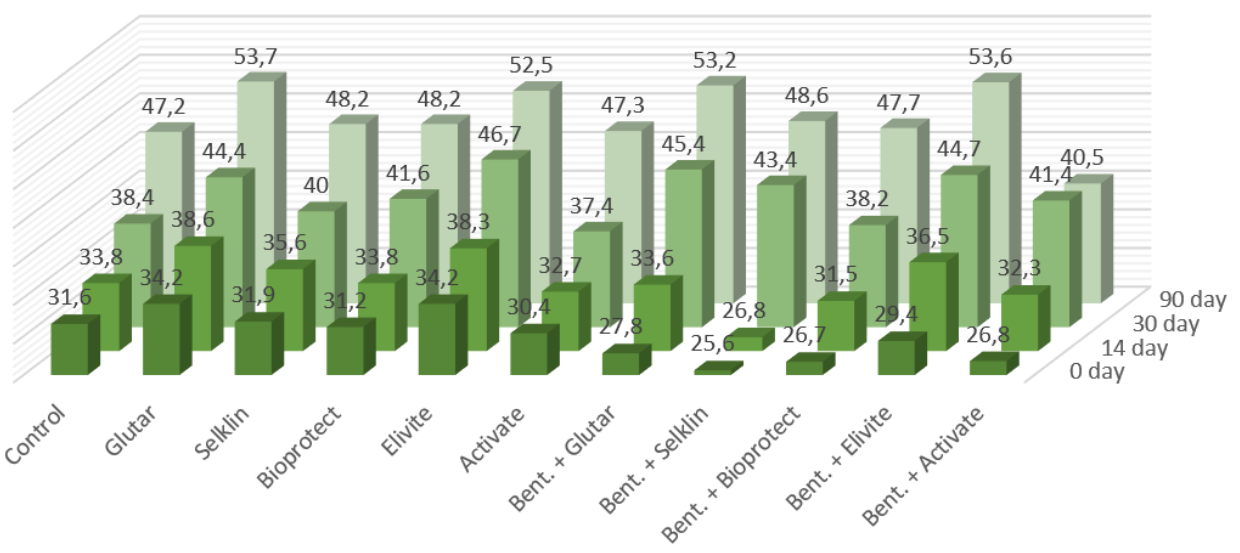

Fig. 4. Value change of antioxidant activity (AOA) in process of secondary fermentation in acratophores, $\mathrm{mg} / \mathrm{dm} 3$, in terms of TROLOX.

Analysis of the results of the studies confirmed the previous data. The use of glutaroma and elivite as well as mixtures thereof in combination with bentonite provided the highest antioxidant activity of sparkling wine in both secondary fermentation methods. These preparations can be recommended to reduce the level of oxidative processes in the production of sparkling wines and Russian champagne.

Taking into account the obtained results and the role of glutathione in oxidation-reduction processes, its accumulation was determined in different variants depending on the conditions of secondary fermentation - in bottles or acratophores. The experiment was carried out in the process of secondary fermentation.

The circulation and fermentation mixtures were made of the same blend of wine materials in which the mass concentration of total sulfur dioxide was $150 \mathrm{mg} / \mathrm{dm}^{3}$ and glutathione was $215 \mathrm{mg} / \mathrm{dm}^{3}$.

Glutathione (GSH) is chemically a tripeptide- $\gamma$-glutamyl cysteinyl glycine, and has an unusual peptide bond between the amino group of cysteine and the carboxyl group of the glutamate side chain: 
<smiles>N[C@@H](CCC(=O)N[C@@H](CS)C(=O)NCC(=O)O)C(=O)O</smiles>

This compound has a very low redox potential, which causes its buffering properties in many redox reactions. Glutathione is a natural antioxidant whose effect exceeds that of ascorbic acid and sulphur dioxide, and under oxidative conditions it is it that is oxidized primarily by reacting with quinones to form stable colorless complexes, contributes to reduction of wort and wine submission:

$$
\begin{gathered}
\mathrm{GSH}+\mathrm{Q} \longrightarrow{\mathrm{GS}-\mathrm{QH}_{2}}_{2 \mathrm{GSH}+\mathrm{H}_{2} \mathrm{O}_{2} \longrightarrow \mathrm{GS}-\mathrm{SG},}^{\longrightarrow} \text { Q - quinone }
\end{gathered}
$$

In addition, it helps to maintain the stability of thiol aroma precursors by forming quinone-glutathione complexes (so-called "grape reaction products" - GRP). The most important role of glutathione in white wort is to react with quinones formed from hydroxycoric acids, caftaric acid to form S-glutathionyl-caftaric acid, which is more stable to enzymatic oxidation, reduces the conquering of wines. Glutathione also plays a protective role due to its reaction with oxidized polyphenols, which it enters earlier than members of grade flavors (e.g. thiols) and other polyphenols.

One function of glutathione in living systems is thought to be the maintenance of ascorbic acid in reduced form. In grapes glutathione accumulates during maturation, with significant fluctuations observed: from 17 to $114 \mathrm{mg} / \mathrm{l}$, at the same time glutathione content in yeast is up to $1 \%$ of dry mass.

In wort, wine and yeast, glutathione is present in both oxidized (GSSG) and reduced (GSH) forms. However, it exhibits antioxidant properties only in reduced form. Protection of wort and young wine material is provided by glutathione concentration from 30 to 100 $\mathrm{mg} / \mathrm{l}$ plus initial concentration, which depends on grape pressing conditions.

The glutathione content of the wine depends on the nitrogen available to yeast. In the case of low levels of nitrogen available to yeast, glutathione is used by yeast as a feed.

The presence of glutathione as a natural antioxidant helps to preserve wine aroma, prevent oxidation and prevent the appearance of aging tones.

The results of the studies showed that the introduction of drugs into the circulation (fermentation) mixture initially resulted in a decrease in glutathione concentration in most test variants. The exception was the variants with the use of glutaroma, selcline, bioproject, in which there was a slight increase in glutathione content due to the presence of this component in the composition of biopreparations. 


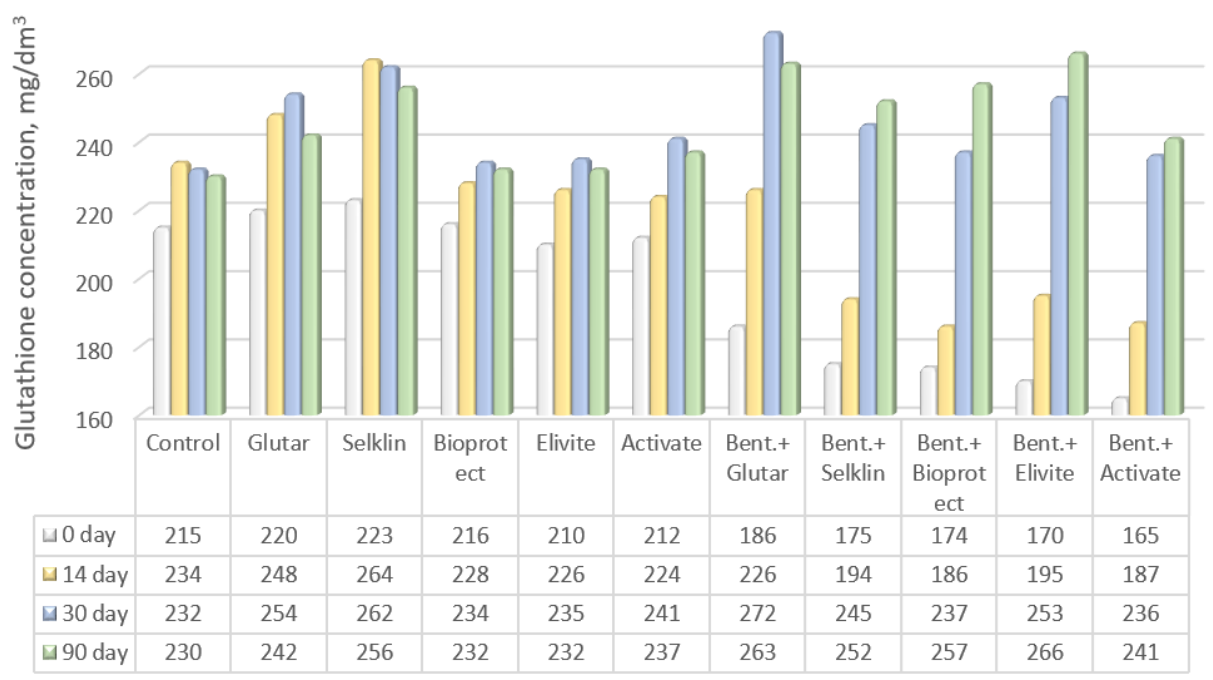

Fig. 5. Glutathione concentration change in process of secondary fermentation in bottles.

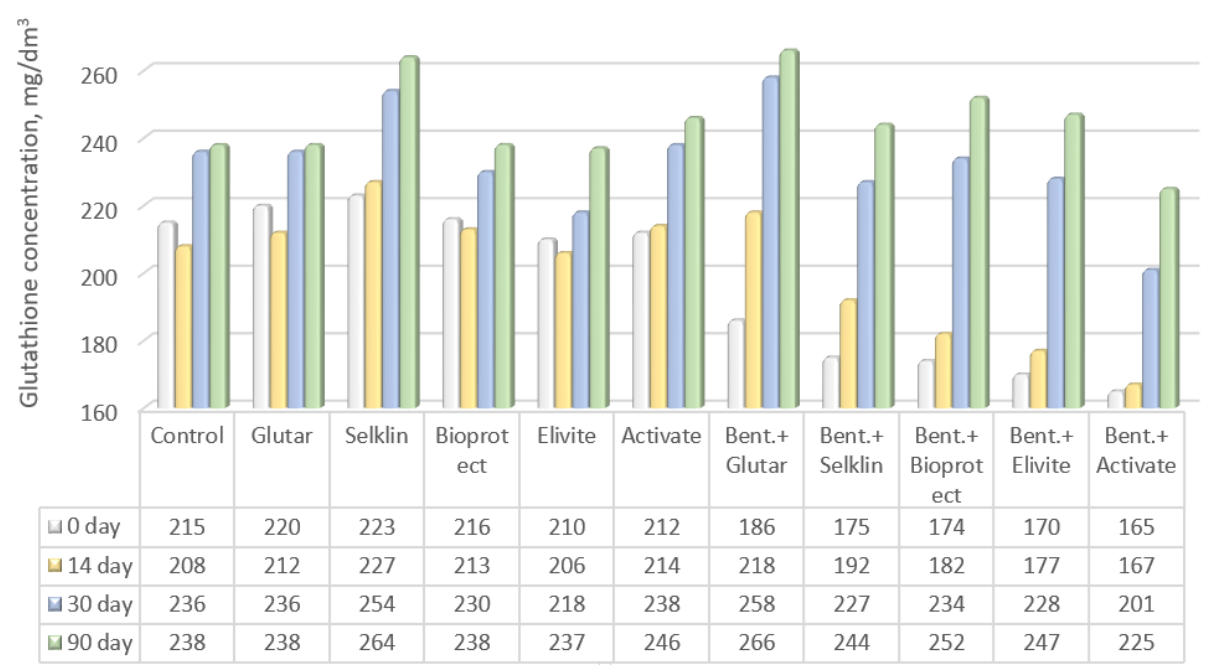

Fig. 6. Glutathione concentration change in process of secondary fermentation in tanks.

During the secondary fermentation of the control variant, there was an increase in glutathione concentration in the first 14 days, after which its concentration remained virtually unchanged during 90 days of observation. Perhaps such dynamics of glutathione formation is related to the stages of yeast cell development: the maximum of its accumulation is in the exponential and stationary phase of cell development.

Introduction of glutaroma and, especially, salcline into the circulation mixture activated the fermentation process and, as a result, the concentration of reduced glutathione increased on the 14th day. Subsequently, its content changed slightly downward.

The introduction of elivite (variant 4) and activite (5) into the circulation mixture caused a slight increase in glutathione by the 30 th days of fermentation.

A different pattern was observed using mixtures of biological preparations and bentonite suspension. There has been a marked increase in glutathione concentration, especially in versions with glutaroma (6), elivite (9) and bioprostect (8). An increase in glutathione was observed throughout the observation period. This is due to the fact that at the same time as 
fermentation, autolithic processes begin in the hermetically closed tank (bottle). There are high-quality and quantitative changes in the oxidation-reduction sphere of the wandering environment: are formed new redox couple with prevalence got into condition, including glutathione the glutathione restored $\rightarrow$ oxidized, acetoin $\rightarrow$ diacetyl, there is an inactivation of oxidizing enzymes. These changes characterize the process of wort fermentation as a reducing technique.

In the secondary fermentation reservoir process, a slightly higher amount of dissolved oxygen is retained in the fermentation mixture. This first oxidizes the glutathione present in the medium, after which its concentration gradually increased. It should be noted that when mixtures of biological preparations and bentonite suspension are used, as in classic fermentation, more glutathione is observed in the wine compared to variants $1-5$, which is associated with activation of the fermentation process by immobilized yeast cells and accumulation of more cell biomass.

\section{Conclusions}

Thus, the carried out studies have shown the expediency of using biopreparations of dry inactivated yeast - glutaroma, elivite and their mixtures with bentonite suspension in secondary fermentation of wine materials both by reservoir and classic bottle method in order to reduce ORP of wine, increase its antioxidant activity, increase the content of reductons.

\section{References}

1. V. Penacho, E. Valero, R. Gonzalez, International Journal of Food Microbiology 153, 176-182 (2012) doi: 10.1016/j.ijfoodmicro.2011.11.005

2. K.M. McMahon, C. Culver, J.C. Castura, C.F. Ross, Food Quality and Preference 59, 14-26 (2017) doi: 10.1016/j.foodqual.2017.01.017

3. A. Borrull, G. López-Martínez, E. Miró-Abella, Z. Salvadó, N. Rozès, Food Microbiology 54, 20-29 (2016) doi: 10.1016/j.fm.2015.11.001

4. R. Martínez-García, Y. Roldán-Romero, J. Moreno, A. Puig-Pujol, J. Carlos Mauricio, T. García-Martínez, Food Chemistry 308, 125555 (2019) doi: 10.1016/j.foodchem.2019.125555

5. L. Canonico, F. Comitini, M. Ciani, Food Microbiology 74, 100-106 (2018) doi: 10.1016/j.fm.2018.03.009

6. I. Benucci, M. Cerreti, D. Maresca, G. Mauriello, M. Esti, Food Chemistry 300, 125174 (2019) doi: 10.1016/j.foodchem.2019.125174

7. C. Ubeda, I. Kania-Zelada, R. Barrio-Galán, M. Medel-Marabolí, M. Gil, Á. Peña-Neira, Food Research International 119, 554-563 (2019) doi:10.1016/j.foodres.2018.10.032

8. P. Di Gianvito, G. Perpetuini, F. Tittarelli, M. Schirone, G. Arfelli, A. Piva, F. Patrignani, R. Lanciotti, L. Olivastri, G. Suzzi, R. Tofalo, Food Research International 109, $552-$ 560 (2018) doi: 10.1016/j.foodres.2018.04.070

9. S. Sartor, I.M. Toaldo, C.P. Panceri, V. Caliari, M.T. Bordignon-Luiz, Food Research International 124, 34-42 (2019) doi: 10.1016/j.foodres.2018.11.012

10. N. López de Lerma, R.A. Peinado, A. Puig-Pujol, J.C. Mauricio, T. García-Martínez, Food Chemistry 250, 22-29 (2019) doi: 10.1016/j.foodchem.2018.01.036

11. C. Berbegal, L. Polo, M. José García-Esparza, V. Lizama, S. Ferrer, I. Pardo, Food Microbiology 78, 25-37 (2018) doi: 10.1016/j.fm.2018.09.016

12. I. Benucci, LWT 118, 108732 (2020) doi: 10.1016/j.lwt.2019.108732 
13. R. Velázquez, E. Zamora, M. Álvarez, M.L. Álvarez, Manuel Ramírez Food Microbiology 59, 150-160 (2016) doi: 10.1016/j.fm.2016.06.006

14. P. Di Gianvito, G. Arfelli, G. Suzzi, R. Tofalo, Alcoholic Beverages 7, 347-386 (2019) doi: 10.1016/B978-0-12-815269-0.00011-8

15. M. José Ruiz-Moreno, J. Manuel Muñoz-Redondo, F. Julián Cuevas, A. MarrufoCurtido, J. Manuel Moreno-Rojas, Food Chemistry 230, 697-704 (2017) doi: 10.1016/j.foodchem.2017.03.048 